\title{
TIPOLOGÍA DE LOS MUNICIPIOS TURÍSTICOS DE MÉXICO A FINES DEL SIGLO XX
}

\author{
E. PROPÍN FREJOMIL y A. SÁNCHEZ-CRISPÍN \\ Instituto de Geografía, UNAM \\ Ciudad Universitaria, México DF MEXICO
}

\begin{abstract}
Resumen: Este trabajo tiene como fin examinar los municipios turísticos de México desde una óptica cuantitativa que permita evidenciar los sitios de concentración de esta actividad económica en el país. Se utilizan cuatro tasas para evaluar el impacto de la intensidad, la penetración, la densidad y el predominio del turismo extranjero, en cada uno de los lugares con mayor dinámica de esta actividad en el territorio mexicano. Se logra, así, tener una imagen más clara de la distribución geográfica de las actividades recreativas en México, que podrá servir de referencia para futuros trabajos sobre el análisis territorial del turismo.
\end{abstract}

Palabras clave: Geografía Económica, turismo, México, América Latina.

\begin{abstract}
This paper is based in the quantification of four major aspects of foreign visitors in Mexico, namely presence, penetration, density and predominance of this type of tourism in the national territory. To achieve this the respective four ratios were calculated for each of the most important tourist municipios in the country. Such a territorial view of tourism can be used as reference for future research in the Geography of tourism in Mexico.
\end{abstract}

Key words: Economic Geography, tourism, Mexico, Latin America.

\section{INTRODUCCIÓN}

Al término del siglo, el turismo es una de las mayores fuentes de divisas para México, después del sector petroquímico y la industria maquiladora. Esta situación puede verse con mayor perspectiva si se tiene en cuenta que, mientras se ha dado una abrupta y cuantiosa caída de los precios internacionales del petróleo en los primeros meses de 1998, el número de turistas extranjeros que han entrado al país no $h a$ descendido en los últimos años. De acuerdo con datos oficiales, entre 1990 y 1995, 
llegaron anualmente al país más de seis millones de personas con el propósito de permanecer en México por más de dos noches (SECTUR, 1997).

\section{EVOLUCIÓN RECIENTE DEL TURISMO EN MÉXICO}

Desde mediados del presente siglo, el turismo ha tenido un lugar destacado en la economía mexicana. Esto se obvia en el seno de la inversión federal, para impulsar distintas actividades económicas, que privilegia al turismo en regiones específicas del país (AGUILAR et al., 1996). En los inicios del turismo masivo, los visitantes extranjeros tenían como destinos principales a los ahora llamados centros tradicionales como Acapulco, que despegaron en pleno contexto de la Segunda Guerra Mundial. La relativa riqueza disfrutada por las sociedades desarrolladas de posguerra permitió los desplazamientos de millones de personas, con motivos de recreación, hacia diferentes sitios, entre ellos México. En el decenio 1960-70, el origen de la mayor parte de los visitantes extranjeros, en el país, era estadounidense. Hacia mediados de los setenta, el gobierno federal inicia los primeros intentos por ordenar el crecimiento del turismo mediante la creación de los llamados Centros Integralmente Planeados, origen de Cancún, Ixtapa-Zihuatanejo, Bahías de Huatulco, Los Cabos y Loreto. A excepción de este último, todos son en la actualidad importantes núcleos de crecimiento del sector turístico y, algunos como Cancún y Los Cabos, han rebasado el contexto nacional para convertirse ya en lugares de referencia en el seno de los flujos internacionales del turismo.

\section{SINÓPSIS DE LOS ATRACTIVOS TURÍSTICOS DE MÉXICO}

La posición geográfica de privilegio que tiene el país, dentro de las zonas tropical y desértica, vecino inamovible de Estados Unidos y con fuertes lazos de parentesco cultural con las naciones de América Latina, explican en buena medida el crecimiento extraordinario, de los últimos dos decenios, que ha experimentado la actividad turística en México.

A continuación se reseñan los elementos del espacio geográfico que atraen a los paseantes extranjeros.

1. Las playas tropicales o del desierto que ofrecen escenarios inigualables para la práctica de distintos deportes acuáticos, desde el surfeo en las aguas del Golfo de California hasta el buceo de primera clase en las costas de la isla de Cozumel en el Mar de las Antillas. En general, la línea litoral de este último mar es más atractiva 
por el color y quietud de sus aguas. Sin embargo, sobre la costa del Pacífico, el turismo irrumpió primero gracias a las condiciones de temperatura superiores a los $26^{\circ} \mathrm{C}$ a lo largo del año, por ejemplo en la llamada Riviera Mexicana ${ }^{1}$. Asimismo, la predicción casi perfecta de ausencia de lluvias en casi ocho meses del año sobre el litoral pacífico, desde la península de Baja California hasta las Bahías de Huatulco, hacen de esta región costera idónea para que el turismo encuentre condiciones favorables de crecimiento y expansión física y se propicie el llamado ecoturismo.

2. Las ciudades coloniales de México, herencia del pasado minero, ejercen una atracción de particular importancia sobre los visitantes extranjeros. Estas localidades se asientan en el centro y centro-norte del país y sus imágenes han sido captadas tanto por libros como por filmes de conocida factura. Entre ellas, la misma Ciudad de México se encuentra como principal centro de actividad turística del país, gracias a ser la sede del gobierno federal y combinar su circunstancia de ciudad colonial con su pasado arqueológico, cercano e interno. Otras ciudades coloniales de importancia son Guanajuato, Zacatecas y Taxco.

3. Los sitios arqueológicos. El pasado de México se atestigua mediante la visita a centros de capital importancia en la vida cultural y económica de los pueblos que habitaban este país antes de la llegada de los españoles. Las diversas culturas de Mesoamérica y Aridoamérica se evidencian ahora por las más de 280 lenguas indígenas detectadas en el territorio nacional. En especial, estos sitios se ubican en las regiones del sur y este del país: Oaxaca, Chiapas y la península de Yucatán. Cada vez es mayor el interés por literalmente desenterrar el magnífico pasado arquitectónico de México, así en los últimos años, a pesar de que los turistas acuden a los tradicionales sitios arqueológicos, se han abierto otros en estados que, con anterioridad, no tenían presencia en este sentido: Puebla, Tlaxcala y Veracruz.

4. Las ciudades fronterizas. La historia del turismo en estas ciudades de México está asociada con diversos factores: las leyes prohibitivas respecto al alcohol en Estados Unidos en el decenio de los treinta, el crecimiento de la industria maquiladora y su consecuente aumento en la actividad comercial y de servicios en estos asentamientos humanos y, quizá más importante, la idea de que las ciudades fronterizas mexicanas frente al escaparate de modernidad de la economía estadounidense, reflejan fielmente ante el paseante extranjero (gringo o no gringo) la idea estereotipada de México y su cultura (ARREOLA y CURTIS, 1993).

\footnotetext{
${ }^{1}$ La Riviera Mexicana es la porción de la costa pacífica mexicana que incluye desde Bahía de Banderas, sobre la cual se asienta Puerto Vallarta, hasta las siete bahias cercanas a Santa María Huatulco (SÁNCHEZ Y PROPÍN, 1996). Esta porción costera de México es segunda, después de Cancún (ahora incluido en la llamada Riviera Maya), en cuanto al impacto que ha causado el turismo en México, a las modificaciones del espacio geográfico de acogida, a la creación de empleos y a la derrama económica generada por las actividades turísticas (DE SICILIA y LÓPEZ, 1998).
} 


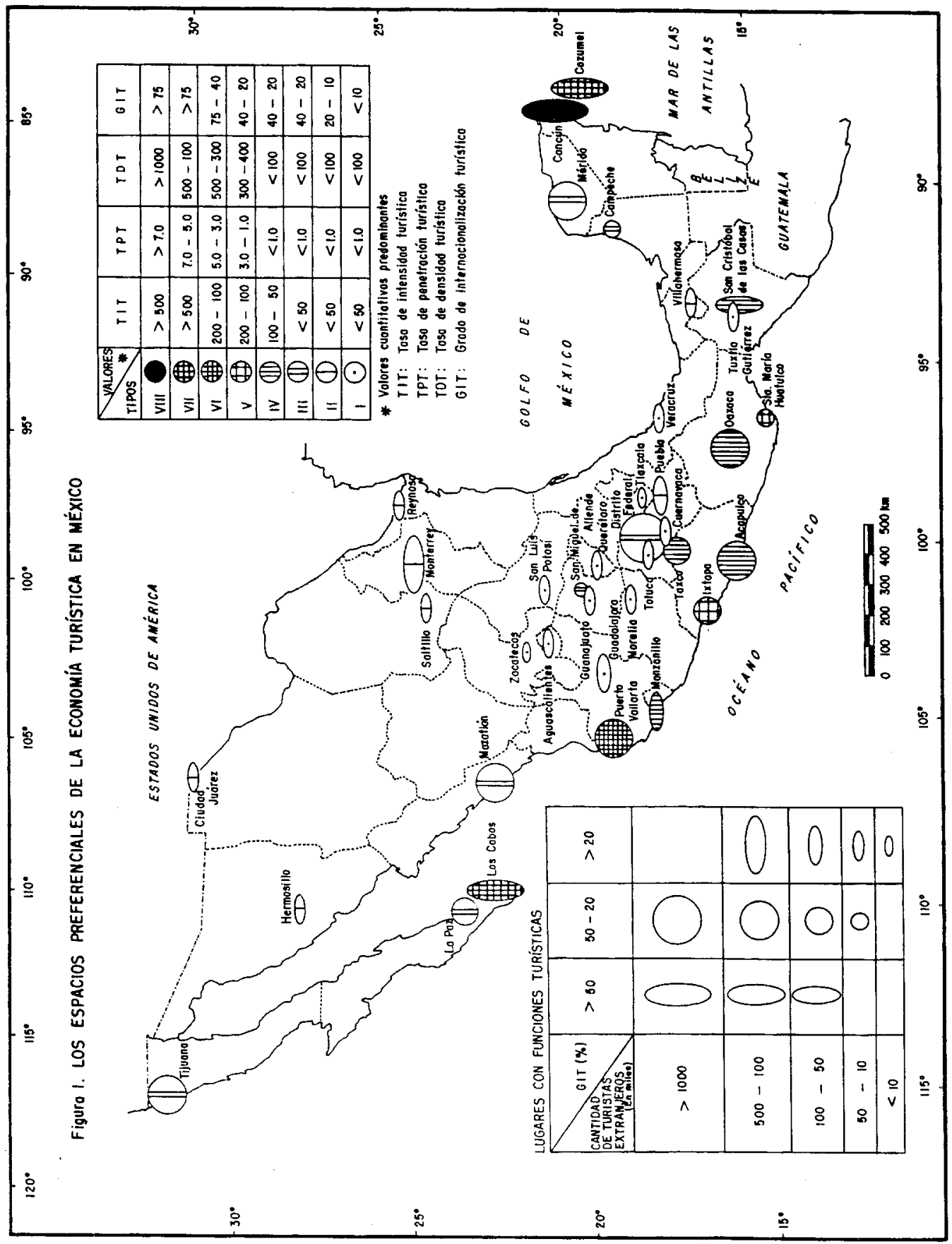


En una proporción significativa, se trata de un turismo arrastrado por el alcohol, las drogas y la prostitución. En este nicho se acomodan ciudades como Tijuana, que es la más visitada del mundo, con más de 40 millones de cruces anuales rumbo a México (PROPÍN et al., 1998), Juárez y Reynosa.

\section{TIPOLOGÍA DE LOS MUNICIPIOS TURÍSTICOS MEXICANOS}

Para poder tener una idea objetiva de cómo se inserta el turismo en distintos sitios de México se calcularon cuatro tasas que mesuran esta actividad en el espacio geográfico (SEZER \& HARRISON, 1995) ${ }^{2}$. Así, la tasa de intensidad del turismo es la relación del número total de visitantes extranjeros respecto a la población de cada municipio mexicano; la tasa de penetración considera las estancias medias de los turistas entre la población local en el lapso de un año; la que se refiere a la densidad del turismo sopesa las estancias medias de los visitantes en el contexto de la superficie del municipio en cuestión, en un año y, finalmente, se obtuvo la relación existente entre el número de visitantes extranjeros respecto al total de turismo registrados en cada municipio ${ }^{3}$. El cuadro 1 contiene los resultados para México y los 37 municipios resultantes. Con base en la consideración global de las cuatro tasas, los municipios turísticos de México se agruparon en ocho tipos mediante el método de tipificación probabilística (PROPÍN y THORMER, 1986). El tipo VIII corresponde a las tasas más altas y el I a las más bajas.

Tipo VIII . El único sitio del país que quedó incluido en esta categoría es Cancún (municipio de Benito Juárez) en el estado de Quintana Roo (Figura 1). En la actualidad, es el sitio turístico mexicano más promovido en el exterior. A consecuencia de ello, el número de turistas extranjeros ha ido en aumento en los últimos años, sólo superado por los registrados en la Ciudad de México. Con lazos internacionales muy fuertes, en especial con la costa oriental de Estados Unidos, este centro ha atraído hacia sí un gran número de enlaces: aéreos y marítimos con el exterior, al que se

\footnotetext{
2 Estos autores proponen el cálculo de cuatro tasas para medir el impacto del turismo en un territorio específico, las tres primeras corresponden a las que mesuran intensidad, penetración y densidad, como las que se obtuvieron para el presente estudio. La cuarta tasa, en el trabajo de Sezer y Harrison se enfoca a ver el origen preferente de los visitantes extranjeros en cada unidad espacial de referencia. En el caso de México, no es posible conseguir este tipo de datos para el nivel municipal. Por eso, se eligió que nuestra cuarta tasa relacionara el número de visitantes extranjeros respecto al total de turistas en cada municipio.

${ }^{3}$ El criterio en el que se basó la elección de estos municipios fue: que hubieran sido registrados más de diez mil turistas extranjeros en la demarcación municipal en el año de 1995. A pesar de no alcanzar esta cifra, el municipio de Zacatecas fue incluido en la lista porque, además de presentar una cifra de turistas extranjeros cerca a los diez mil (9605), en años anteriores ahí se registraron más de doce mil visitantes no mexicanos. Se optó por utilizar los datos de 1995 porque de este año también había datos oficiales acerca del total de población de cada municipio.
} 
encuentra más ligado que con el interior de México. El espacio económico que separa a la mayoría de la población mexicana respecto a Cancún explica, en gran medida, que la gran cantidad de visitantes a este centro del Mar de las Antillas (enunciado como Mar Caribe para efectos promocionales), sean extranjeros. En los cuatro índices calculados, Cancún obtuvo las cifras más altas.

\begin{tabular}{|c|c|c|c|c|c|c|c|c|}
\hline Municipios & $\begin{array}{l}\text { Area } \\
\left(\mathrm{km}^{2}\right)\end{array}$ & Población & $\begin{array}{r}\text { Visitantes } \\
\text { extranjeros }\end{array}$ & $\begin{array}{c}\text { Turistas- } \\
\text { noche }\end{array}$ & TIT & TPT & TDT & GIT \\
\hline Acapulco & 1882,6 & 687292 & \begin{tabular}{r|}
375395 \\
\end{tabular} & 1600125 & 54,61 & 0,63 & 232,86 & 21,1 \\
\hline Aguascalientes & 1762,5 & 582827 & 10441 & 24593 & 1,79 & 0,03 & 3,82 & 4,1 \\
\hline Campeche & 3812,6 & 204533 & 45873 & 47989 & 22,42 & 0,06 & 3,44 & 36,5 \\
\hline Cancún $^{4}$ & 1664 & 311696 & 1665839 & 9069040 & 534,44 & 7,97 & 1493,1 & 77,3 \\
\hline Gozumel & 864 & 48385 & 243458 & 1225752 & 503,16 & 6,94 & 388,68 & 78,5 \\
\hline Cuernavaca & 244,7 & 316782 & 26196 & 64862 & 8,26 & 0,05 & 72,62 & 8,7 \\
\hline Distrito Federal $^{2}$ & 1499 & 8489000 & 1685833 & 4265672 & 19,85 & 0,13 & 779,63 & 21,3 \\
\hline Guadalajara & 187,9 & 1633216 & 134840 & 305084 & 8,25 & 0,05 & 444,83 & 9,9 \\
\hline Guanajuato & 1010,7 & 128171 & 37926 & 54185 & 29,59 & 0,11 & 14,68 & 12,9 \\
\hline Hermosillo & 14890,2 & 559154 & 31617 & 62218 & 5,65 & 0,03 & 1,14 & 15,5 \\
\hline $\operatorname{|xtapa}^{3}$ & 1921,5 & 87161 & 121708 & 697861 & 139,63 & 2,19 & 99,5 & 34,6 \\
\hline Juárez $^{4}$ & 4853,8 & 1011786 & 69491 & 101283 & 6,86 & 0,02 & 5,71 & 11,9 \\
\hline La Paz & 14756,2 & 182418 & 50349 & 111664 & 27,6 & 0,16 & 2,07 & 25,4 \\
\hline Los Cabos & 2414,3 & 71031 & 390479 & 1497225 & 549,73 & 5,77 & 169,9 & 87,1 \\
\hline Manzanillo & 1578,4 & 108584 & 59614 & 193267 & 54,9 & 0,48 & 33,54 & 18,4 \\
\hline Mazatlán & 3068,5 & 357619 & 159305 & 897056 & 44,54 & 0,68 & 80,09 & 22,6 \\
\hline Mérida & 854,4 & 649770 & 219936 & 452439 & 33,84 & 0,18 & 145,07 & 44,2 \\
\hline Monterrey & 451,3 & 1088143 & 142470 & 281788 & 13,09 & 0,07 & 171,06 & 16,5 \\
\hline Morelia & 1335,9 & 578061 & 26271 & 35989 & 4,54 & 0,01 & \begin{tabular}{|l|}
7,38 \\
\end{tabular} & 4,7 \\
\hline Oaxaca & 85,4 & 244827 & 133437 & 301702 & 54,5 & 0,33 & \begin{tabular}{|l|}
966,98 \\
\end{tabular} & 28,9 \\
\hline Puebla & 524,3 & 1222569 & 65513 & 13 & 5,35 & 0,02 & 52,26 & 11,2 \\
\hline Puerto Vallarta & 1300,7 & 8876 & 361523 & 2179464 & 241,21 & 3,98 & 459,07 & 43,6 \\
\hline Querétaro & 759,9 & 559222 & 10948 & 21417 & 1,95 & 0,01 & 7,72 & 3,2 \\
\hline Reynosa & 2961,3 & 337053 & 26034 & 46192 & 7,72 & 0,03 & 4,27 & 10,2 \\
\hline Saltillo & 6837 & 527979 & 28347 & 42973 & 5,36 & 0,02 & 1,72 & 14,3 \\
\hline S. Cristóbal las C. & 484,4 & 116729 & 80880 & 117012 & 69,28 & 0,27 & 66,18 & 50,2 \\
\hline S. Luis Potos & 1353,3 & 625466 & 27804 & 63570 & 4,44 & 0,02 & $.12,86$ & 9,6 \\
\hline S. Miguel Allende & 1496,3 & 118769 & 32143 & 81277 & 27,06 & 0,18 & 14,88 & 22,9 \\
\hline S. María Huatulco & 579,2 & 25242 & 37537 & 253726 & 148,7 & 2,75 & 120,01 & 24,4 \\
\hline Taxco & 343 & 95144 & 61593 & 83438 & 64,73 & 0,24 & 66,64 & 39,9 \\
\hline Tijuana & 1392,5 & 991592 & 178697 & 279742 & 18,02 & 0,07 & 55,03 & 23,6 \\
\hline Tlaxcala & 44,6 & 63423 & 3568 & 9210 & 5,62 & 0,03 & 56,57 & 2,1 \\
\hline Toluca & 377,3 & 564476 & 16330 & 46763 & 2,89 & 0.02 & 33,95 & 8,3 \\
\hline Tuxtla Gutiérrez & 139,1 & 386185 & 20412 & 22293 & 5,28 & 0,01 & 43,9 & 7,7 \\
\hline \begin{tabular}{|l} 
Veracruz \\
\end{tabular} & 241 & 425140 & 32407 & 72575 & 7,62 & 0,04 & 82,5 & 4,4 \\
\hline Villahermosa $^{5}$ & 1765,4 & 465449 & 29821 & 46599 & 6,4 & 0,02 & 7,23 & 10,6 \\
\hline Zacatecas & 719,6 & 118742 & 9605 & 14699 & 8,08 & 0,03 & 5,59 & 3,5 \\
\hline MEXICO & 1967183 & 91158290 & 6717928 & 24910299 & 7,37 & 0,07 & 3,46 & 24,4 \\
\hline \multicolumn{9}{|c|}{ 1. El municipio dondes se asienta Cancún se llama Benito Juárez; 2. Para el Distrito Federal se cornpil $\delta$ el dato de todas sus } \\
\hline \multicolumn{9}{|c|}{ delegaciones poilticas; 3 . Ixtapa incluye a Zihuatanejo, ambos asentamientos humanos situados en el municipio José Azueta; } \\
\hline \multicolumn{9}{|c|}{$\begin{array}{l}\text { 4. Juárez es el municipio de Chihuahua limitrofe con El Paso, Texas: } 5 \text {. Villahermosa se ubica en el municipio Centro del } \\
\text { estado de Tabasco. }\end{array}$} \\
\hline \multicolumn{9}{|c|}{ TIT: Tasa de intensidad turistica } \\
\hline \multicolumn{9}{|c|}{ TPT: Tasa de penetración turistica } \\
\hline \multicolumn{9}{|c|}{ TDT: Tasa de densidad turlstica } \\
\hline \multicolumn{9}{|c|}{ GIT: Grado de internacionalización turistica } \\
\hline
\end{tabular}


Tipo VII. Dos municipios mexicanos se incluyen en este tipo: Cozumel y Los Cabos. Uno insular, el otro muy aislado y terminal dentro del territorio mexicano (Figura 1), ambos comparten la característica de que su economía se articule en medida mayoritaria alrededor de la actividad turística que, al igual que el caso de Cancún, es de factura extranjera. Los visitantes no nacionales provienen, en forma abrumadora, de Estados Unidos, del flanco oriental para el caso de Cozumel y de la costa occidental, en especial californiana, en Los Cabos. En estos espacios, el turismo internacional fuerza la presencia de una economía dolarizada, basada en el arreglo estacional de la llegada de cruceros y de muy débiles lazos con el hinterland inmediato. Aun cuando ambos municipios se encuentran en los extremos del territorio nacional, las peculiaridades de su función como centros turísticos, en cuanto a número de visitantes extranjeros por año, así como su estancia y predominio respecto a la totalidad de la actividad turística local, los coloca en el tope de la jerarquía nacional, sólo después de Cancún. Es de esperarse que, en un futuro inmediato, estos dos lugares de la trama territorial del turismo en México experimenten crecimientos físicos extraordinarios, derivados de una afluencia cada vez mayor del turismo internacional.

Tipo VI. Un solo caso se acomoda en este tipo de municipio turístico en el país, se trata de Puerto Vallarta, ubicado en la llamada Riviera Mexicana. Este es un sitio con tradición turística que se remonta al decenio de los cuarenta, cuando México aún no descollaba en ese ámbito. El grueso de los visitantes que llegan a Vallarta lo hacen por vía aérea y proceden del oeste de Estados Unidos, en particular de California y Arizona. Este puerto ha registrado una expansión física extraordinaria, en cuanto a infraestructura para el turismo se refiere, que ha impactado al municipio vecino de Bahía de Banderas, en Nayarit, donde se han ubicado varios de los desarrollos turísticos nuevos, financiados con capital extranjero, estadounidense y británico. Puerto Vallarta, dentro de la Riviera Mexicana, ha superado a Acapulco como destino preferente del turismo internacional que llega a la zona.

Tipo V. Dos municipios quedan en esta categoría de lugares dedicados al turismo en México: Huatulco e Ixtapa-Zihuatanejo, sobre la Riviera Mexicana (Figura 1). Ambos son resultado de la aplicación de políticas del gobierno federal, desde el decenio de los setenta, para impulsar los llamados Polos de Desarrollo Turístico (al igual que Los Cabos y Cancún). Se trata de lugares de reciente implantación, como centros de servicios para la recreación, con incipiente crecimiento derivado del sector, tanto en términos demográficos como económicos. Sus ligas con el exterior son todavía débiles, comparadas con las que disponen los municipios de los tipos precedentes, y sus nexos hacia el interior del país son importantes, aunque no en la medida de los que tienen otros centros de playa, como Acapulco o Manzanillo. Hasta este grupo, los visitantes extranjeros, respecto al total de la población de cada municipio, rebasa el $100 \%$ de esta cifra (Cuadro 1). 
Tipo IV. Este grupo, conformado por cinco municipios (Oaxaca, Acapulco, Taxco, Manzanillo y San Cristóbal de las Casas), se presenta en el sur del país; excepto Manzanillo, los municipios pertenecen a las entidades más pobres de México: Chiapas, Guerrero y Oaxaca (Figura 1). Se conforma tanto por sitios de playa, afamados y de tradición en el mercado del turismo internacional, como por ciudades coloniales que atraen importantes flujos hacia sí debido a su relativa cercanía con la Ciudad de México ${ }^{4}$. Aquí se incluyen a un centro internacional de turismo, venido a menos frente a la fuerte competencia de los municipios incluidos en categorías superiores, se trata de Acapulco, que si bien ha perdido una parte substancial del mercado de visitantes extranjeros, ha conservado y aumentado la cantidad de turistas nacionales que tienen como destino a este puerto. Las peculiaridades de este grupo son valores medios de la participación de visitantes extranjeros respecto al total y una reducción notoria de las tasas de intensidad, penetración y densidad turística en relación con los tipos anteriores.

Tipo III. Los grupos restantes tienen en común las tasas calculadas más bajas, excepto la de la participación del turismo extranjero sobre el total de visitantes anuales. Esa tasa diferencia los tres tipos que a continuación se exponen (Figura 1). E1 tipo III corresponde a un grupo numeroso de municipios turísticos de México (siete en total). En Èl se incluyen lugares muy distintos entre sí, desde fronterizos (Tijuana) hasta ciudades coloniales (Mérida, San Miguel de Allende y Campeche), con inclusión de la Ciudad de México (Figura 1). Se trata de sitios con registro elevado de turistas extranjeros, respecto al número total anual de visitantes. De hecho, Tijuana es 1 a ciudad más visitada del mundo, con un promedio de 40 millones de personas que llegan a ella, la mayoría de los cuales no pernoctan en sus instalaciones de hospedaje sino que permanecen unas horas en territorio mexicano, en busca de diversión, en especial nocturna y de fines de semana. La Ciudad de México, si bien conserva todavía los valores más altos de todo el país, en cuanto a número de extranjeros registrados como visitantes, con cerca de 2 millones de personas, la proporción de éstos no rebasa el $40 \%$ del total de turistas que visitaron la ciudad en 1995.

Tipo II. Ocho municipios del país quedaron en esta categoría. Se trata de lugares del norte del país, en particular fronterizos, cuya proporción de turistas extranjeros, respecto al total de visitantes registrados en 1995, no supera el 20\%. Además, en este grupo se incluyen ciudades coloniales, como Guanajuato y Puebla, y una gran urbe del norte mexicano: Monterrey. En el caso de ésta, la dinámica económica de otros sectores,

\footnotetext{
${ }^{4}$ Llama la atención el hecho de que en este grupo quede incluido el municipio de San Cristóbal de las Casas, con un porcentaje alto de turistas extranjeros respecto al total de visitantes en el año 1995. La interpretación a esta lectura de datos estaría enfocada a considerar que el conflicto social y armado en Chiapas, en vigor desde 1994, ha atraído un número considerable de extranjeros hacia esa región del país, cuya puerta de acceso más utilizada es, precisamente, San Cristóbal.
} 
como el industrial, el comercial y el de servicios que no tienen que ver con el turismo, desdibujan el impacto local del turismo.

Tipo I. Es el grupo de municipios turísticos de México más numeroso. Incluye diez lugares, distintos tanto por su dinámica económica pero casi todos concentrados en 1 a core area del país. Quedan en esta categoría, sitios coloniales, un puerto, ciudades alrededor de la de México y una gran urbe en el occidente: Guadalajara. Se trata de sitios que reciben muy pocos turistas extranjeros, tanto en proporción a la población local como en función del número total de visitantes registrados en 1995. Varios de estos municipios reciben en forma residual el turismo que se dirige a lugares más importantes, como la Ciudad de México; tal es el caso de Toluca, Querétaro, Cuernavaca y Morelia.

\section{CONCLUSIÓN}

Existen en México distintos tipos de municipios turísticos en razón de la cantidad de visitantes extranjeros que a ellos se dirigen. Los resultados obtenidos en esta investigación apuntan a una tipología de lugares dedicados al turismo en México que no tiene que ver, en forma directa, con las categorías que maneja la Secretaría de Turismo del gobierno federal, ya que éstas no fueron establecidas en función de la dinámica que hoy en día presenta el turismo internacional en distintas regiones del país.

Los tipos comprendidos entre VIII y V contienen los lugares donde, en 1 a actualidad, los visitantes extranjeros tienen un impacto vertebral en la articulación del espacio económico local y regional. Sitios como Cancún, Cozumel, Los Cabos y algunos de la Riviera Mexicana, como Vallarta, Huatulco e Ixtapa-Zihuatanejo, son los nodos convergentes del turismo internacional cuando éste opta por visitar México. Las grandes ciudades, como México, Guadalajara y Monterrey, al tiempo que lugares de abolengo en el contexto del turismo internacional, como Acapulco, han quedado desplazados y no son más los lugares preferentes de destino. Las ciudades fronterizas, como Tijuana, disponen de una dinámica turística intensa y distinta de los otros centros del país por su condición de lugar de tránsito binacional.

En suma, los tipos encontrados revelan la diversidad de lugares turísticos que existen en México y la función económica que éstos ejercen sobre sus espacios de atracción, tanto regionales como exteriores. 


\section{NOTAS}

1. La Riviera Mexicana es la porción de la costa pacífica mexicana que incluye desde Bahía de Banderas, sobre la cual se asienta Puerto Vallarta, hasta las siete bahías cercanas a Santa María Huatulco (véase Sánchez y Propin, 1996). Esta porción costera de México es segunda, después de Cancún (ahora incluido en la llamada Riviera Maya), en cuanto al impacto que ha causado el turismo en México, a las modificaciones del espacio geográfico de acogida, a la creación de empleos y a la derrama económica generada por las actividades turísticas (cf. De Sicilia y López, 1998).

2. Estos autores proponen el cálculo de cuatro tasas para medir el impacto del turismo en un territorio específico, las tres primeras corresponden a las que mesuran intensidad, penetración y densidad, como las que se obtuvieron para el presente estudio. La cuarta tasa, en el trabajo de Sezer y Harrison se enfoca a ver el origen preferente de los visitantes extranjeros en cada unidad espacial de referencia. En el caso de México, no es posible conseguir este tipo de datos para el nivel municipal. Por eso, se eligió que nuestra cuarta tasa relacionara el número de visitantes extranjeros respecto al total de turistas en cada municipio.

3. El criterio en el que se basó la elección de estos municipios fue: que hubieran sido registrados más de diez mil turistas extranjeros en la demarcación municipal en el año de 1995. A pesar de no alcanzar esta cifra, el municipio de Zacatecas fue incluido en la lista porque, además de presentar una cifra de turistas extranjeros cerca a los diez mil (9605), en años anteriores ahí se registraron más de doce mil visitantes no mexicanos. Se optó por utilizar los datos de 1995 porque de este año también había datos oficiales acerca del total de población de cada municipio.

4. Llama la atención el hecho de que en este grupo quede incluido el municipio de San Cristóbal de las Casas, con un porcentaje alto de turistas extranjeros respecto al total de visitantes en el año 1995. La interpretación a esta lectura de datos estaría enfocada a considerar que el conflicto social y armado en Chiapas, en vigor desde 1994, ha atraído un número considerable de extranjeros hacia esa región del país, cuya puerta de acceso más utilizada es, precisamente, San Cristóbal.

\section{BIBLIOGRAFÍA}

AGUILAR, A., GRAIZBORD, B. y SÁNCHEZ-CRISPÍN, A. (1997): Las ciudades medias y el desarrollo regional en México. Consejo Nacional para la Cultura y las Artes. México.

ARREOLA, D. y CURTIS, J. (1993): The Mexican Border Cities. Landscape Anatomy and Place Personality. The University of Arizona Press. Tucson.

DE SICILIA, R. Y LÓPEZ, A. (1998): "Distribución geográfica de los municipios turísticos de México". Notas. 2, 1-11, Instituto Nacional de Estadística, Geografía e Informática. Aguascalientes, México.

INEGI (1996): Conteo de Población, 1995. Instituto Nacional de Estadística, Geografía e Informática. Aguascalientes, México.

PROPÍN, E., SÁNCHEZ-CRISPÍN, A. y LOPEZ, A. (1998): "Situación geográfico-económica del turismo en el extremo norte de América Latina: el corredor Tijuana-Rosarito-Ensenada". Revista de Geografía Norte Grande. Universidad Católica de Chile. Santiago, Chile (en prensa). 
PROPÍN, E. y THORMER, R. (1986): Un nuevo enfoque metodológico de la regionalización económica de la República de Cuba. Wissenschaftliche Mitteilungen. Leipzig, Alemania.

SÁNCHEZ-CRISPÍN, A. y PROPIN, E. (1996): "Estructura territorial de la actividad turística en la Riviera Mexicana a fines del siglo XX". Memorias del IV Congreso de Ciencias de la Tierra. Instituto Geográfico Militar. Santiago, Chile (en prensa).

SECTUR (1997): Estadísticas de la actividad turística de México. Secretaría de Turismo. México.

SEZER, H. \& HARRISON, A. (1995): "Tourism in Greece and Turkey: an economic view for planners". Tourism. The State of the Art. 74-84. Wiley. Chichester, Gran Bretaña. 